\title{
HISTÓRIAS DA PSICOLOGIA NO CEARÁ: ENTREVISTA COM GERCILENI CAMPOS ${ }^{1}$
}

\author{
Francisco Silva Cavalcante Junior \\ André Feitosa de Sousa"
}

\author{
HISTORIES OF PSYCHOLOGY IN THE CEARÁ: \\ INTERVIEW WITH GERCILENE CAMPOS
}

\section{HISTORIAS DE LA PSICOLOGÍA EN CEARÁ: ENTREVISTA CON GERCILENE CAMPOS}

\begin{abstract}
A professora doutora Maria Gercileni Campos de Araújo, mais conhecida como Gercileni Campos, ou simplesmente Gercy para os amigos, foi uma das pioneiras no desenvolvimento da Psicologia no Ceará, mais especificamente sendo a primeira psicóloga concursada e contratada para ensinar no curso de Psicologia da Universidade Federal do Ceará (UFC). Gercileni Campos partira de Fortaleza em 1969, a fim de estudar Psicologia em Recife, considerando a inexistência do curso na cidade, e viria a obter o primeiro lugar no vestibular para o referido curso na Faculdade de Filosofia do Recife (FAFIRE), à época pertencente à Universidade Federal de Pernambuco. Graduada em Psicologia no ano de 1973, Gercileni foi laureda como a melhor aluna de todos os cursos da FAFIRE naquele ano, recebendo o "Prêmio universitário Banorte". Em 1974, Gercileni, que a essas alturas já ensinava na FAFIRE foi convidada pela Prof ${ }^{a}$. Maria Isolda
\end{abstract}

Bezerra de Menezes para vir prestar concurso público para uma vaga de professora no curso de Psicologia da UFC, fundado naquele ano e carente de psicólogos em seus quadros docentes - a fundação da própria Universidade ocorreu vinte anos antes, em 1954. Convite aceito e aprovação no concurso, Gercileni passa a ensinar a primeira turma de Psicologia da UFC, já em 1975, responsabilizandose pelas disciplinas de "Introdução à Psicologia" e "Psicologia da Personalidade".

No ano de 1977, participa de um Workshop em Recife, no qual participou Carl Rogers, um dos fundadores da Psicologia Humanista e criador da Abordagem Centrada na Pessoa (ACP). Em 1979, facilita, juntamente com Theresse Amelie Tellegen, docente da USP, um workshop em Gestalt-Terapia para a primeira e segunda turma do curso de Psicologia da UFC. Foi o primeiro grupo de Gestalt-

1 Entrevista publicada anteriormente em versão reduzida em Cavalcante Jr, F. S. \& Souza, A. F. (2006, 11 de junho). Para ser terapeuta é preciso estar disponível para a vida. Diário do Nordeste. Disponível em: <http://verdesmares.globo.com/ entrevista/comversa_entrevista.asp?CodigoEntrevista=238>. (Acesso em 11/06/2006).

* Doutor em Reading and Writing Instruction. Professor titular no Mestrado em Psicologia da Universidade de Fortaleza - Unifor.

\# Graduando em Psicologia da Universidade de Fortaleza - Unifor e bolsista de Iniciação Científica (PBICT/Funcap/Unifor). 
Terapia realizado em Fortaleza. Logo depois, em 1981, realiza o primeiro Workshop em Gestalt-Terapia e ACP de Fortaleza, juntamente com Afonso Henrique da Fonseca, psicólogo de Maceió, tornando-se referência em Psicologia Humanista e influenciando pelo menos duas gerações inteiras de psicólogos no Ceará.

Decorrentes mais de três décadas, a professora Gercileni, hoje psicoterapeuta e psicanalista, com Doutorado em Psicologia Clínica pela Universidade de São Paulo e especialista em Psicanálise pela Universidade de Campinas, é a escolhida para ser homenageada pela Cátedra RELUS $2006^{2}$, por sua efetiva contribuição no desenvolvimento da Psicologia Clínica em Fortaleza, particularmente no que concerne o enfoque fenomenológico-existencial da Abordagem Centrada na Pessoa e da Gestalt-Terapia, ao tempo em que estas abordagens engatinhavam no Brasil.

Decerto, a experiência da Prof ${ }^{a}$ Gercileni Campos é testemunha inolvidável de um importante recorte histórico e epistemológico, muito embora francamente desconhecido, na Psicologia do Ceará. Trata-se de temperaturas, sentimentos, percepções; os bastidores internos de uma construção psicológica que nos remete à segunda metade do século XX no Brasil e que, ousamos acreditar, não podem fazer parte de um livro perdido. É, também, a maneira com a qual propugnamos o título de Professora Emérita para quem, de fato, representa o coração incansavelmente pulsante do cuidado pelo ser humano. Que seu exemplo e o poder de sua simplicidade possa nos inspirar.

\section{ENTREVISTA}

Professora Gercileni, a Sra. poderia falar um pouco como se sucedeu a introdução dos estudos acadêmicos da Psicologia no Ceará?

Gercileni: Antes de tudo, gostaria de agradecer a homenagem que me foi prestada pela Cátedra RELUS 2006 do Mestrado em Psicologia da UNIFOR, fato que justifica essa entrevista. A respeito da pergunta, para ser precisa, não disponho dessa informação, se considerarmos que em 1975, quando retornei de Recife, onde fui estudar Psicologia, disciplinas de Psicologia certamente já integravam os currículos de alguns cursos

2 Evento, realizado pela Rede Lusófona de Estudos da Felicidade - RELUS e ocorrido em 23 de junho de 2006, de conclusão do primeiro ano do Grupo de Estudos e Práticas Interdisciplinares da Felicidade aplicada à construção de uma cultura de sustentabilidade e bem-estar coletivos, na perspectiva da Psicologia Humanista de orientação positiva. na área das Humanidades na UFC. No que diz respeito, propriamente, ao curso de graduação em Psicologia, este foi fundado em 1974, no Departamento de Ciências Sociais e Filosofia, e, sendo a primeira psicóloga concursada e contratada para ensinar no curso, deparei-me com contingências de toda ordem, atreladas a um curso que se iniciava, como as instalações físicas precárias, a falta de recursos econômicos para a contração de novos professores, o déficit de material descartável/consumo. Essas limitações, todavia, não reduziam o entusiasmo e a garra com os quais os poucos professores, Isolda Bezerra de Menezes, Glaucia Menezes, Padre Suzenito, Ricardo Lincoln e eu mesma, trabalhavam para que o curso se firmasse com qualidade no cenário da Universidade Brasileira. Recordo-me ainda da participação de Edda Augusta Quirino Simões, profissional paulista que retornou a São Paulo em meados de 1975. As dificuldades foram inúmeras, relacionadas também à qualificação acadêmica do escasso corpo docente. Desse modo, logo me ausentei para cursar, em 1976-77, o Mestrado em Psicologia Clínica na Universidade de São Paulo. Nesse ínterim, outros professores foram contratados pela UFC, ao mesmo tempo em que colegas de outros Departamentos vieram colaborar com o curso de Psicologia. Lembrome agora dos colegas Edgar Linhares, Neide Monteiro, José Telmo Valença, Tarcísio Diniz, Aluízio Pinheiro, Natércia Lima Verde, Célia Julião, Orozimbo Leão, Sônia Leão, Padre Dourado, Beth Mota, Beth Schilling, Taís Furtado e Tânia (ambas falecidas), Ana Lage, César Wagner, Vivina Balbino, Elda Carvalho, dentre outros - que me perdoem pela falha da memória. A primeira turma formada em Psicologia pela UFC, em 1978, forneceu outros professores para o curso, dentre os quais Ângela Pinheiro, Ângela Marques, Mônica Távora, Vilma Paiva, Lilian Adeodato e Ana Luísa Mendes. Acho oportuno, aqui, destacar que a Prof ${ }^{a}$ Ângela Marques elaborou um trabalho de mestrado a respeito da história do curso de Psicologia na Universidade Federal do Ceará.

Professora Gercileni, a Sra. poderia discorrer acerca do desenvolvimento da Clínica Psicólogica a partir da sua vivência?

Gercileni: Em 1975, quando cheguei de Recife, havia pouquíssimos consultórios de Psicologia em Fortaleza. Talvez, nem mesmo consultórios, mas clínicas que integravam o profissional psicólogo. Fui muito bem acolhida por uma colega do Recife, aqui radicada, Wedja Granja, a quem sou grata por ter me 
disponibilizado sua sala para que eu atendesse meus primeiros pacientes de Fortaleza. Havia, ainda, algumas clínicas de reabilitação motora, nas quais o psicólogo integrava a equipe profissional, ao lado de médicos, terapeutas ocupacionais, assistentes sociais, fisioterapeutas - cheguei, inclusive, a trabalhar numa delas, dirigida pelo Dr. Píndaro (seria Clínica de Reabilitação Motora do Ceará?). Todavia, a dificuldade de interlocução, pela escassez de profissionais da mesma área, era mais uma razão (além das questões afetivas) que me fazia viajar quinzenalmente para Recife, a fim de manter os atendimentos dos meus pacientes naquela cidade e continuar tendo um grupo de supervisão em clínica, sob a orientação do Prof. Lúcio Flávio Campos (também cearense), emérito professor da FAFIRE e da Universidade Católica do Recife - em torno de quem se agrupavam os psicólogos de orientação humanista naquela capital. É também desse contexto, o curso de formação em Psicodrama Triádico, inaugurado no Brasil por Pierre Weil, e orientado, no Recife, por Lúcio Flávio Campos e Maria Ayres. Em Fortaleza, de importância fundamental para a organização dos psicólogos no Ceará, cumpre citar o psicólogo Eduardo Costa (de saudosa memória), funcionário da REFESA e primeiro presidente da secção cearense do Conselho Regional de Psicologia. Jane Costa, esposa do Eduardo, Sissy e Socorro Saldanha davam a sua contribuição como psicólogas clínicas ligadas à reabilitação profissional no INSS (não sei se é esta a sigla correta para a época). Em 1977, veio ao Brasil, para realizar um grande workshop na Fazenda de Arcozelo, no Rio de Janeiro, o psicólogo Carl Rogers e sua equipe (John Wood, Maria e Jack Bowen, e Maureen Miller O’Hara - esta última, encantou-se pelo Brasil, chegando a morar seis meses no país. Maureen aprendeu o português e continuou vindo ao Brasil até 1985, aproximadamente, às vezes demorando-se longos períodos por aqui. Sempre sensível, inteligente, estudiosa e desconcertantemente sincera. Hábil no manejo de grandes grupos contribuiu significativamente para a formação dos primeiros Gestalt-terapeutas no Brasil, influenciando, ainda, ao movimento da Abordagem Centrada neste país). Antes do evento em Arcozelo, Rogers realizou um workshop de quatro dias, para 400 pessoas, em Recife, do qual participei. Novamente em Recife, após Arcozelo, John Wood e Maureen Miller facilitaram um workshop de dez dias do qual participei, sobre o trabalho com sonhos em Gestalt-Terapia. Esse workshop foi fundamental na orientação do meu trabalho clínico, e, na verdade, para a minha vida. No início de 1979, facilitei, juntamente com Therese Amelie Tellegen (Gestalt-terapeuta, docente da USP e minha professora num curso de
Gestalt do Sedes Sapientie, em São Paulo), um workshop em Gestalt-Terapia para a primeira e a segunda turmas do curso de Psicologia na UFC, sendo esse o primeiro grupo realizado em Fortaleza nessa abordagem. Em fins de 1979, voltei de São Paulo, onde cursava o mestrado em Psicologia Clínica na USP, e, aqui, encontrei um cenário mais desenvolvido, com a atuação de vários profissionais. Nesse momento, tive, na gentileza das colegas Beth Mota e Cristina, a oportunidade de compartilhar o mesmo consultório. Naquela clínica, também trabalhavam Fátima Vasconcelos e Veriana Colaço, além de outros profissionais que não me lembro dos nomes agora. Nessa época, realizei juntamente com Afonso Henrique Lisboa da Fonseca, um psicólogo de Maceió, o I Workshop de Gestal-Terapia e Abordagem Centrada na Pessoa, em Fortaleza, no ano de 1981. Sendo um workshop residencial foi gratificante perceber a confiança e acompanhar o processo dos participantes no trabalho realizado. Importa registrar que, naqueles tempos, sobrava-me energia e disposição para organizar e promover atividades diversas, de maneira que se seguiram vários outros grupos, cabendo destacar a vinda à Fortaleza de Maureen Miler O'Hara e, posteriormente, John K. Wood, que a meu convite, desenvolveram wokshops para grupos fechados e palestras públicas na UFC. Nos anos 80, devo mencionar a contribuição do Centro de Desenvolvimento Humano (CDH) e da clínica Psicologia da Pessoa e do Grupo, onde também trabalhei. Nesta última, estavam diletos amigos, dentre os quais, Virginia Moreira, Célio Freire, Ana Frota, Georges Boris e Carlene Vasconcelos. Desse grupo, surgiram trajetórias acadêmicas e profissionais singulares. Nos anos 70, até meados dos anos 80, davase na Psicologia o florescimento de um ideário que perseguia o desenvolvimento das potencialidades humanas. Os movimentos de contestação social e político-econômica ao redor do mundo clamavam pela transformação, pela justiça, pela abertura. A influência do pensamento existencialista ainda se disseminava, convocando a que cada um, envolto em suas contingências, se responsabilizasse pelas escolhas feitas na vida. No Brasil, a Ditadura Militar provocou a emergência da luta contra a censura, contra a usurpação dos direitos civis e humanos, contra a ausência de liberdade. Estendia-se na cultura Brasileira de então, o impacto dos Beatles..., da minissaia..., do movimento hippie que marcaram os anos $60 \ldots$ E a Psicologia também partilhava e expressava esse ideário. As pessoas precisavam se juntar... um fato, por si só, proibido na Ditadura... e 
juntar-se para pensar e compartilhar, com autenticidade, suas vidas, seus medos, seus sonhos, seus ideais... Assim, os "Grupos de Encontro" e workshops vivenciais tiveram, muitas vezes, funções políticas. Participei e testemunhei. Os trabalhos psicológicos em grandes grupos, geralmente residenciais, durante fins de semana, ou ainda de dez dias, mais ou menos, quando feitos com responsabilidade e cuidado por parte dos facilitadores, representavam um espaço de reflexão e de vivências interpessoais enriquecedoras, de desenvolvimento e expressão da criatividade. Poderia distinguir três modalidades de grupos, aqueles voltados para o treinamento de profissionais e estudantes da Psicologia e da Medicina; os grupos de encontro abertos à comunidade, com outros objetivos e perfil de participantes; além dos grupos terapêuticos semanais. Tive o privilégio de participar ou facilitar vários desses grupos, dentro e fora do Ceará. Mas não só isso: a produção acadêmica se fazia presente através das apresentações de muitos trabalhos em seminários, simpósios e congressos nacionais e internacionais. A reflexão teórica segue até hoje. Na clínica privada, além do atendimento individual, também atendia a grupos terapêuticos semanais. $\mathrm{Na}$ Universidade, desde 1980, passei a supervisionar estágio curricular na área clínica, com o enfoque em Gestalt-Terapia. Entre 1983-1987, coordenei e orientei o primeiro curso de formação de Gestalt-terapeutas do Ceará. Em 1986-87, já estava em São Paulo, e vinha regularmente para dar continuidade à referida formação. Em São Paulo, tive a oportunidade de compor o Conselho Diretor do Centro de Estudos de Gestalt de São Paulo por um biênio. Desse curso de formação, vários terapeutas tornaramse professores da UFC e da UNIFOR. Com um deles, Georges Boris, amigo próximo e professor da UNIFOR, colaborei na facilitação de grupos no seu curso de formação de terapeutas.

Professora Gercileni, a Sra. poderia nos contar acerca das experiências que marcaram sua trajetória profissional?

Gercileni: Tive bons mestres, e com isso quero dizer mestres que não tentaram me formatar, e que foram capazes de acolher as minhas inquietações, as minhas dúvidas, incentivando-me a desenvolver o meu estilo pessoal, com liberdade e rigor. Eu queria, então, destacar Lúcio Campos, Maureen Miller e Thérese Tellegen, que, em momentos e situações diferentes da minha vida, estimularam-me e acreditam no meu potencial. O trabalho que desenvolvi durante muitos anos, foi, sem dúvidas, influenciado pelos ensinamentos destes mestres. Em particular, Maureen Miller, mas não ela apenas, que ocupava a direção dos estudos gestálticos na equipe de Carl Rogers, desenvolveu a partir da Abordagem Centrada na Pessoa e da GestaltTerapia um modo próprio na condução de grupos terapêuticos. Eu e Afonso Henrique Lisboa da Fonseca fomos, no Nordeste, herdeiros dessa tradição. Do meu ponto de vista, é essa tradição que virá a subsidiar e fomentar o que, hoje, se chama psicologia fenomenológica-existencial. De 1981 a 1986 aconteceram seis "Encomum" - Encontros Comunitários -, com participantes oriundos de todo o Brasil, sendo os primeiros em Sapucaí Mirin, e os três últimos em Belo Horizonte. Participei dos cinco primeiros e co-facilitei o último - todos experiências muito ricas. Para além da experiência clínica, houve uma professora, muito importante, Ana Lúcia Dias Schliemann, docente no curso de graduação em Psicologia, no Recife, com quem aprendi sobre a persistência, a disciplina e o entusiasmo, e também a professora Alba Guerra, com quem estudei Técnicas Projetivas, e me ensinou a tentar olhar em profundidade, a perscrutar o que está aparentemente posto... isso foi super importante. Passados tantos anos, percebo que a liberdade e o rigor não são mutuamente excludentes, e que é possível ser sério sem ser sisudo, que não basta ser sabido, é preciso perseguir a sabedoria... ser sabido é pouco. Nesta trajetória, sou avessa ao dogmatismo, às reduções, às identificações imaginárias, à ingênua profissão de fé num saber teórico, qualquer que seja ele. Aprendi que é preciso viver para fazer a clínica. Não convém ser o terapeuta que sacrifica o cinema, o teatro, o museu, o papo com os amigos... Uma boa dose de curiosidade favorece uma compreensão mais ampla acerca da pluralidade dos mundos vividos pelos pacientes. Para ser terapeuta é preciso estar disponível para a vida. Gostaria, também, falar dos meus supervisionandos - na Universidade e na clínica privada... a seu respeito, tenho sempre lembranças muito carinhosas, pela possibilidade de construirmos, juntos, coisas em que acreditamos. A UFC sempre foi a minha causa, e a minha casa... Outros bons mestres foram os meus pacientes, especialmente aqueles considerados os mais difíceis, os que me desalojavam de um lugar de saber, e me convocavam a reinventar a escuta, a reconhecer os limites do cânone posto e a sair da mesmice. Deixar Fortaleza e morar em São Paulo, nas duas ocasiões em que lá vivi (mestrado e doutorado), foi fundamental na minha vida... aquela cidade que eu imaginava inóspita e hostil revelou-se como lugar de encontros, de profundas transformações. O paulistano, tido como reservado num primeiro momento, quando se faz amigo, é, de 
fato, um amigo mesmo, e lá, tenho, ainda hoje, uns poucos bons amigos que foram, também, companheiros no percurso profissional. Durante o período do Doutorado em São Paulo, entre 1986 e 1989, tive a oportunidade de integrar-me a um grupo de profissionais, coordenado pela Prof ${ }^{a}$ Ada Pellegrini e reunidos em torno do enfoque psicanalítico-sistêmico, onde estudávamos e ministrávamos cursos introdutórios sobre temáticas da família, e que, em 1987, veio a institucionalizar-se como o Centro de Estudos de Família de São Paulo (CEFASP). São também dessa mesma época vários cursos que me despertaram para novos interesses, especialmente aqueles oferecidos pela FUNARTE, em São Paulo, acerca dos "Sentidos da Paixão", "O Olhar", "O Desejo" etc. Ainda mais significativo foi o curso de especialização em Psicanálise na UNICAMP, onde lecionavam os professores Bento Prado Jr., Zelico Laparic, Luiz Roberto Monzani, Osmyr Faria Gabbi Jr., dentre outros. Nessa época, também fiz análise com uma profissional filiada à IPA, durante quatro anos, quatro vezes por semana. E o meu encontro com a Psicanálise foi intenso, apaixonante e transformador. À experiência analítica, somavam-se os estudos em Psicanálise na USP e na UNICAMP, os grupos de supervisão, e, certamente, a minha clínica se transformaria. Desde lá, implementei atividades na direção de uma formação psicanalítica, que perdura até hoje, porque se trata de um contínuo tornar-se. Já em Fortaleza, fiz análise durante três anos, quatro vezes por semana. Desde maio de 2002, tenho ido mensalmente à São Paulo, onde fico por cinco dias para análise, supervisão e grupos de estudo. Desta forma, o Doutorado alargou as minhas fronteiras e os meus interesses. Minha tese, defendida em 1992 e intitulada "Histórias de Amor no Cordel e Psicoterapia", fez-me percorrer o imaginário nordestino de lendas, histórias, fábulas, contadas e cantadas no Cordel, ao mesmo tempo em que me exigiu a busca da referência mítica, desde os mitos gregos, atravessando as concepções de amor na tradição judaico-cristã, na Cortesia e na modernidade. A narrativa amorosa no Cordel para ser compreendida exigia esse percurso. No meio do caminho, dei-me conta de que o poeta que contava as histórias era um narrador, e, então, foi precioso recorrer a Walter Benjamim. A realização desse trabalho trouxe de volta as minhas origens nordestinas, e, ao mesmo tempo, convocou-me para o diálogo com o universo das fábulas, das lendas e dos mitos que povoam o imaginário pelos vários cantos do mundo, e de volta à UFC, pude oferecer uma disciplina optativa de "Mitologia e Psicanálise". Em Fortaleza, o diálogo psicanalítico se fez através de um grupo autogerido, integrado por Valton Miranda, Roberto Nóbrega, Sônia Lobo, Galba Lobo, e eu, cujos encontros transcorriamse uma vez por semana. Tenho gratas recordações dessa troca estimulante. Após o Doutorado, tive outro grande mestre, o filósofo Manfredo Araújo de Oliveira, no curso de especialização em Filosofia da Linguagem na UFC. Suas aulas, ao meu ouvido aprendiz, apontavam, a um só tempo, para a tragicidade e o prazer da aventura filosófica. Na UFC, então, permaneci até fins de 1997, quando, no Brasil, houve uma retirada coletiva de professores vinculados a universidades federais, temerosos que o Governo viesse a suprimir direitos previdenciários adquiridos... fui, então, uma dos que se aposentaram. Condição esta, todavia, que não me impediu de permanecer colaborando na UFC, sobretudo na direção da Revista de Psicologia, por uns dois anos, aproximadamente. Com mais tempo livre, venho me dedicando à clínica, grupos de supervisão e participação em eventos acadêmicos, bancas de mestrado e doutorado no Brasil. De todo modo, quero dizer que essas palavras não pretendem convencer uma história oficial, posto que, certamente, outros atores e autores nessa jornada podem enriquece-la com seus pontos de vista e falar de suas experiências.

Endereço para correspondência: Francisco Silva Cavalcante Junior. Universidade de Fortaleza - Unifor, Mestrado em Psicologia, Av. Washington Soares, 1321 - Bloco N sala 13, Cep 60811-905, Fortaleza-CE. E-mail: cjunior@unifor.br

Recebido em 18/01/2007 Aceito em 07/03/2007 